\title{
Míranos! Look at Us, We Are Healthy! An Environmental Approach to Early Childhood Obesity Prevention
}

\author{
Zenong Yin, Ph.D.,' Deborah Parra-Medina, Ph.D., '2 Alberto Cordova, Ph.D.,' \\ Meizi He, Ph.D.,' Virginia Trummer, M.S.,' Erica Sosa, Ph.D.,' Kipling J. Gallion, M.S., \\ Amanda Sintes-Yallen, M.P.H., ${ }^{2}$ Yaling Huang, Ph.D., ${ }^{3}$ Xuelian Wu, Ph.D., ${ }^{4}$ \\ Desiree Acosta, M.S., ${ }^{2}$ Debra Kibbe, M.S., ${ }^{5}$ and Amelie Ramirez, DrPH ${ }^{2}$
}

\begin{abstract}
Background: Obesity prevention research is sparse in young children at risk for obesity. This study tested the effectiveness of a culturally tailored, multicomponent prevention intervention to promote healthy weight gain and gross motor development in lowincome preschool age children.

Methods: Study participants were predominantly Mexican-American children $(n=423$; mean age $=4.1 ; 62 \%$ in normal weight range) enrolled in Head Start. The study was conducted using a quasi-experimental pretest/posttest design with two treatment groups and a comparison group. A center-based intervention included an age-appropriate gross motor program with structured outdoor play, supplemental classroom activities, and staff development. A combined center- and home-based intervention added peer-led parent education to create a broad supportive environment in the center and at home. Primary outcomes were weight-based $z$-scores and raw scores of gross motor skills of the Learning Achievement Profile Version 3.

Results: Favorable changes occurred in $z$-scores for weight (one-tailed $p<0.04$ ) for age and gender among children in the combined center- and home-based intervention compared to comparison children at posttest. Higher gains of gross motor skills were found in children in the combined center- and home-based $(p<0.001)$ and the center-based intervention $(p<0.01)$. Children in both intervention groups showed increases in outdoor physical activity and consumption of healthy food. Process evaluation data showed high levels of protocol implementation fidelity and program participation of children, Head Start staff, and parents.

Conclusion: The study demonstrated great promise in creating a health-conducive environment that positively impacts weight and gross motor skill development in children at risk for obesity. Program efficacy should be tested in a randomized trial.
\end{abstract}

\section{Introduction}

$\mathrm{O}$ besity remains on the rise among MexicanAmerican and low-income children in the United States. ${ }^{1}$ Prevalence of childhood obesity was $20 \%$ among Head Start program enrollees in predominantly Hispanic South Texas, compared to $15 \%$ nationally. ${ }^{2}$ Poor diet, ${ }^{3,4}$ physical inactivity, ${ }^{5,6}$ and lack of access to nutritious food and activity opportunities at school and home $\mathrm{e}^{7,8}$ are major contributing factors to high obesity rates in low-income preschool children. Current evidence points to the importance of early-age obesity prevention because childhood obesity persists into adulthood, ${ }^{9-11}$ and weight loss through intensive lifestyle interventions in adults is challenging and difficult to sustain. ${ }^{12-14}$

Environmental modifications both at childcare centers ${ }^{15}$ and homes ${ }^{7}$ are essential to alter the obesogenic environment surrounding low-income preschool age minority children. ${ }^{16}$ Effective, family-oriented intervention contributes to long-term weight control, ${ }^{17,18}$ but is sparse for this population group. ${ }^{12,15,19}$

In response to these gaps, we tested a culturally tailored, multicomponent obesity prevention intervention,

\footnotetext{
'Department of Health and Kinesiology, The University of Texas at San Antonio, San Antonio, TX.

${ }^{2}$ Institute for Health Promotion Research, The University of Texas Health Science Center at San Antonio, San Antonio, TX.

${ }^{3}$ The College of Management, Beijing Sport University, Beijing, China.

${ }^{4}$ School of Physical Education, Southwest University, Chongqing, China.

${ }^{5}$ The Georgia Health Policy Center, Georgia State University, Atlanta, GA.
} 
Miranos! Look at Us, We Are Healthy! (Miranos!), in predominantly Mexican-American preschool children enrolled in Head Start. Miranos! provided staff training and wellness programs, structured outdoor play, supplemental classroom activities, and parent engagement-components demonstrated as effective in our previous pilot studies ${ }^{20}$ and based on current consensus for effective preschool obesity interventions. ${ }^{7,21,22}$ Miranos! was designed to answer two questions: (1) To what extent a center-based intervention and a combined center- and home-based intervention have favorable impacts on healthy weight gain, gross motor skill development, physical activity, and healthy eating of children across the spectrum of obesity versus a comparison group and (2) to what extent the intervention activities are feasible and acceptable in a preschool setting. Process data are provided to evaluate implementation fidelity, intervention exposure, and staff and parent responses.

\section{Methods}

\section{Study Sample}

Miranos! was conducted in four Head Start centers on the west and southwest sides of San Antonio, Texas, which are among the most economically disadvantaged neighborhoods in the state. ${ }^{23,24}$ On the basis of our previous pilot, ${ }^{20}$ prevalence of obesity $(25.3 \%)$ and overweight $(24.6 \%)$ was high among children residing in the same neighborhoods according to the CDC Growth Chart. ${ }^{25}$ Children $(n=423)$ enrolled in the centers were predominantly Hispanic $(90 \%)$ and had a mean age of 4.1 years at pretest (see Table 1 for center and participant characteristics). Participant recruitment was conducted by recruitment flyers and letters to parents.
Children received a coloring book if they returned a consent form regardless of consent status. Parental consent for participation in the study was received from 384 children ( $91 \%$ response rate).

\section{Study Design}

The study, designed to test the effectiveness of an obesity prevention program on healthy weight gain and gross motor skill development in four Head Start centers, used a quasi-experimental pretest/posttest design with two treatment groups and a comparison group. Two centers received a center-based intervention, one center received a combined center- and home-based intervention, and one center served as comparison. Each received $\$ 300$ in their general fund for participation. The comparison center received intervention materials and implementation training upon completion of the study. Geographical clustering as well as cost of study protocol implementation (staff travel and program cost) were the main considerations for deciding the treatment assignment. For example, the comparison center was 5 miles away from the intervention centers to avoid cross contamination. Study protocol was approved by the Institution Review Boards at The University of Texas at San Antonio and The University of Texas Health Science Center at San Antonio.

\section{Miranos! Intervention Description}

Miranos! employed theories of early childhood development and a systems approach to modify daily eating and physical activity behaviors and provide an interactive, supportive learning environment for preschool children. ${ }^{12}$ Preschool years (ages $3-5$ ), a critical time in children's development of food consumption and physical activity preferences and habits, are heavily influenced by

Table I. Demographics of Head Start Centers and Participants in the Míranos! Study

\begin{tabular}{|c|c|c|c|c|}
\hline & All centers & Comparison & $\begin{array}{l}\text { Center-based } \\
\text { intervention }\end{array}$ & $\begin{array}{l}\text { Center- and } \\
\text { home-based } \\
\text { intervention }\end{array}$ \\
\hline Number of centers & 4 & I & 2 & I \\
\hline Number of classrooms & 21 & 6 & 14 & 5 \\
\hline Number of administrative staff & 8 & 2 & 4 & 2 \\
\hline Number of support staff & II & 2 & 7 & 2 \\
\hline Center enrollment & 423 & 97 & 179 & 80 \\
\hline$\%$ of children with parental consent & 91 & 95 & 87 & 96 \\
\hline$\%$ of consented children tested at pretest & 88 & 83 & 85 & 100 \\
\hline$\%$ of female children participated in pretest & 52 & 53 & 51 & 55 \\
\hline$\%$ of children tested at both pre- and posttest & 88 & 91 & 85 & 86 \\
\hline$\%$ of female children participated in both pre- and posttest & 52 & 49 & 49 & 58 \\
\hline$\%$ of parents returned parental surveys $(n=197)^{\mathrm{a}}$ & 55 & 80 & 56 & 98 \\
\hline Mean age (standard deviation) of children participated in pretest & $4.1(0.56)$ & $4.1(0.52)$ & $4.1(0.60)$ & $4.2(0.54)$ \\
\hline $\begin{array}{l}\text { Mean age (standard deviation) of children at pre-test who } \\
\text { participated in both pre- and posttest }\end{array}$ & $4.1(0.57)$ & $4.1(0.53)$ & $4.2(0.62)$ & $4.2(0.53)$ \\
\hline
\end{tabular}


childcare providers, parents, and families and are a prime opportunity for behavioral intervention..$^{21,26-28}$ Following a systems approach, Míranos! targeted change agents at multiple levels and in multiple contexts (center and home environment, staff training and technical support, staff wellness, parent education, and cultural integration) to create synergy for lasting changes in physical activity and dietary behaviors in preschool children. ${ }^{28}$ With support and participation from Head Start center administrators and staff, Miranos! integrated culturally tailored strategies ${ }^{15}$ : A gross motor skills program with structured outdoor play, ${ }^{6}$ integration of health literacy into classroom activities ${ }^{29-32}$ staff development and wellness, ${ }^{7}$ and engagement of parents for support at homes. ${ }^{7}$ Figure 1 depicts the behavioral targets and expected changes in health outcomes in Miranos!. Miranos! was implemented in two stages. Stage 1 (October, 2010, to January, 2011) established intervention program components and staff training. Stage 2 (January to April, 2011) implemented all program components over an 18 -week period. Table 2 describes the objectives, intervention activities, delivery, and training related to each intervention component.

Center-based intervention. For the gross motor skills program, the research team trained Head Start teachers and paraprofessional staff to implement a gross motor skills program during daily outdoor play (30-45 minutes) using Activity Cards and equipment supplied by the study. ${ }^{33}$ Activity Cards included lesson plans to increase activity levels and teach age-appropriate gross motor skills in a structured group format for outdoor and indoor settings. The Activity Cards were designed by a physi- cal education specialist according to principles of motor development and were reviewed by a motor development expert. Teachers were also trained to use age-appropriate movement music CDs and a dance DVD that provided guided gross motor and dance activities. Teachers were also encouraged to use them for additional physical activities (15-20 minutes) during recess and class transitions. Before Miranos!, children had unstructured, free play on the playground while teachers and paraprofessionals monitored from a distance. During Miranos! teachers provided structured play activities for the first 15-20 minutes and remained engaged with children during free play for the rest of the play period. Teachers, with help initially, independently identified daily activities, directed structured play activities with demonstrations and modeling, and set up play equipment for the outdoor play.

Supplemental classroom activities were based on the Sesame Street Workshop Healthy Habits for Life (HHL) resource kit, a bilingual health education program developed by child health experts using Sesame Street characters to promote physical activity and healthy eating habits in children ages $3-5 .{ }^{34}$ HHL has nine activity modules with short, age-appropriate physical activities, hands-on games, and interactive DVD activities that can be integrated into daily center routines. We supplemented HHL with movement music CDs and 16 children's storybooks with nutrition and physical activity themes that were used during story time, recess, and transitions. We also used food-tasting activities and contests to promote healthy eating (water, low-fat or skim milk, fruits, vegetables, and healthy snacks) during lunch and snacks. The nine

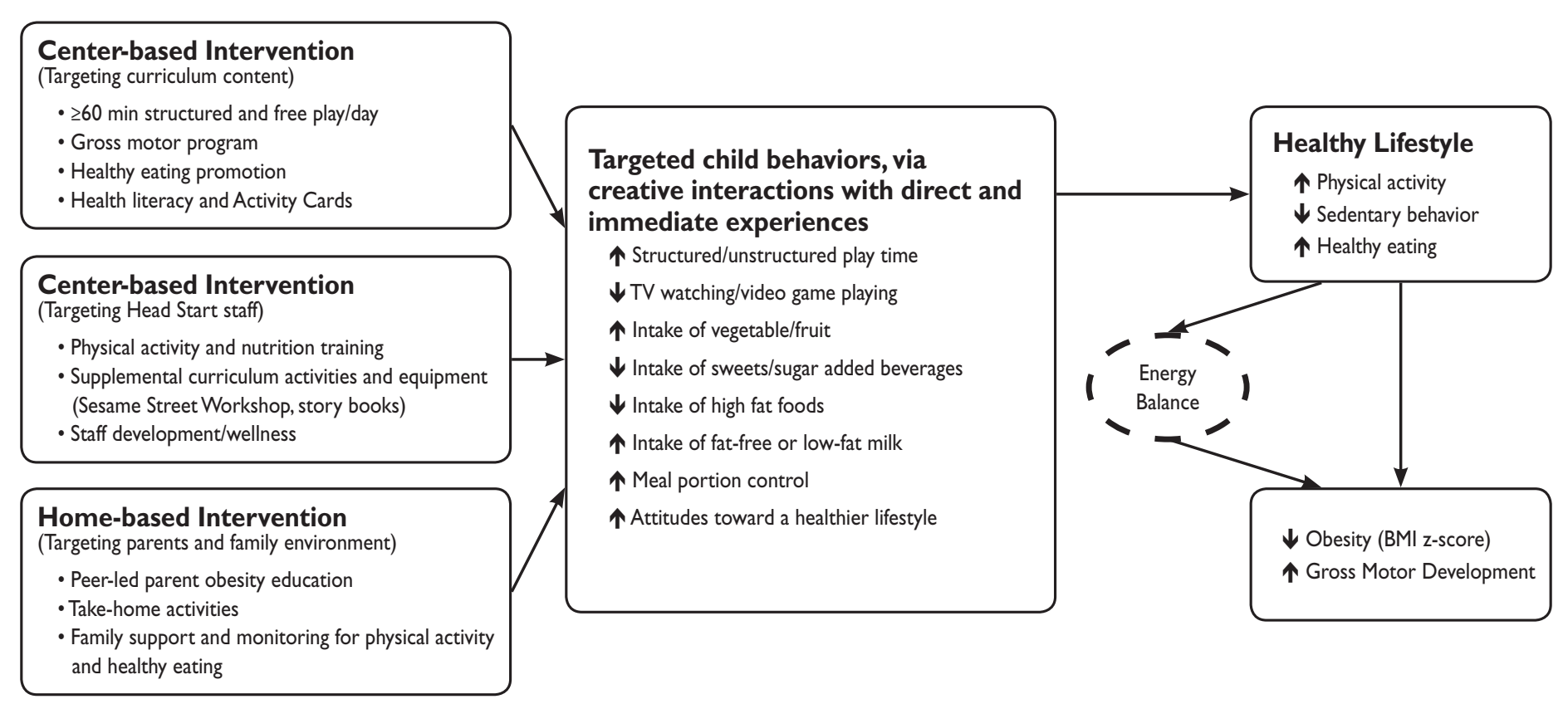

Miranos! Look at Us, We Are Healthy! An Environmental Approach to Early Childhood Obesity Prevention

Figure 1. Miranos! Look at Us, We Are Healthy! Intervention Model. 
modules were implemented over 18 weeks ( 2 weeks per module) to promote health literacy in children. ${ }^{35}$ Teachers were asked to use all activities for each module at least once during the 2 weeks. Two center directors and one experienced teacher developed a biweekly schedule and guide for teachers to integrate Miranos! supplemental classroom and gross motor activities into daily routines. Using the schedule and guide, teachers developed their own weekly lesson plans, which were submitted to center directors prior to beginning a HHL module. Parents of children in both treatment groups received eight bilingual newsletters about HHL activities at the center and tips for supporting their children in learning healthy habits at home.

To address staff development, Head Start teachers, paraprofessionals, and assistant center directors of intervention centers attended a 6-hour training during inservice at the beginning of the school year. This initial training provided general background and introduced the intervention strategies for center-based intervention activities. Follow-up trainings (4 hours) were conducted to address specific topics related to center-based intervention components. There was no certification of training completion. However, all staff participated in the training because these sessions were offered as part of daily staff activities or mandatory staff meetings. Head Start teachers and paraprofessionals have very limited training on nutrition and physical activity, therefore the staff development focused on increasing their health literacy (i.e., knowledge in obesity, nutrition, and physical activity) and teaching skills (i.e., role-modeling, skill demonstration, and leading outdoor activities). Head Start center personnel could voluntarily participate in a wellness program, which offered free health screenings, health newsletters, exercise instructions and equipment (pedometer and resistance band), and counseling on healthy habits.

Home-based intervention. Miranos! aimed to create a home environment conducive for healthy eating and physical activity by providing a home-based intervention at one center - the combined center- and home-based intervention. The objective was to increase health literacy on obesity, nutrition, and physical activity among parents and family members and provide at-home activities. Head Start centers require parents/guardians to physically sign their child in and out of class. Seizing on this opportunity to engage parents, seven parents were trained as peer educators to deliver an educational series on obesity prevention to other parents/guardians during dismissal

\begin{tabular}{|c|c|c|c|c|}
\hline & \multicolumn{3}{|c|}{ Center-based intervention } & \multirow[b]{2}{*}{ Home-based intervention } \\
\hline & $\begin{array}{l}\text { Gross motor } \\
\text { skills program }\end{array}$ & $\begin{array}{c}\text { Supplemental classroom } \\
\text { activities }\end{array}$ & Staff development & \\
\hline Objectives & $\begin{array}{l}\text { - Providing at least } 60 \text { minutes } \\
\text { of structured and free play } \\
\text { daily } \\
\text { - Increasing intensity level } \\
\text { - Developing gross motor } \\
\text { skills }\end{array}$ & $\begin{array}{l}\text { - Developing positive } \\
\text { attitudes and preference for } \\
\text { nutritious foods and physical } \\
\text { activity } \\
\text { - Shaping healthy eating habits } \\
\text { - Developing gross motor } \\
\text { skills } \\
\text { - Increasing health literacy }\end{array}$ & $\begin{array}{l}\text { - Encouraging staff serving as } \\
\text { role models for children and } \\
\text { parents } \\
\text { - Improving staff knowledge } \\
\text { and skills in gross motor } \\
\text { development, physical } \\
\text { activity, and nutrition } \\
\text { - Improving staff wellness }\end{array}$ & $\begin{array}{l}\text { - Developing supportive home } \\
\text { environment for healthy } \\
\text { eating and physical activity } \\
\text { - Increasing health literacy } \\
\text { on obesity, nutrition and } \\
\text { physical activity }\end{array}$ \\
\hline $\begin{array}{l}\text { Intervention } \\
\text { activities }\end{array}$ & $\begin{array}{l}\text { - Míranos! activity cards } \\
\text { - Movement music CDs for } \\
\text { gross motor activities } \\
\text { - Dance DVD } \\
\text { - Provision of gross motor } \\
\text { activity equipment }\end{array}$ & $\begin{array}{l}\text { - Activities from Sesame } \\
\text { Street Workshop Healthy } \\
\text { Habits for Life (HHL) } \\
\text { resource kit } \\
\text { - Children's story books } \\
\text { with nutrition and physical } \\
\text { activity themes } \\
\text { - Míranos! activity cards } \\
\text { - Food tasting activities during } \\
\text { snack times } \\
\text { - Race to Health Contests }\end{array}$ & $\begin{array}{l}\text { - Staff health screenings } \\
\text { - Staff exercise program } \\
\text { (pedometer and resistance } \\
\text { band exercise) } \\
\text { - Staff walking contests } \\
\text { - Staff nutrition education } \\
\text { - I4 Staff health newsletters }\end{array}$ & $\begin{array}{l}\text { - Six peer-led parent obesity } \\
\text { education sessions } \\
\text { - Six take-home activity bags } \\
\text { - I4 Health newsletters for } \\
\text { family members }\end{array}$ \\
\hline $\begin{array}{l}\text { Delivery of } \\
\text { intervention }\end{array}$ & $\begin{array}{l}\text { - Head Start staff } \\
\text { - Research assistants }\end{array}$ & $\begin{array}{l}\text { - Head Start staff } \\
\text { - Research assistants }\end{array}$ & $\begin{array}{l}\text { - Head Start staff } \\
\text { - Research staff }\end{array}$ & $\begin{array}{l}\text { - Peer parent educators } \\
\text { - Research assistants }\end{array}$ \\
\hline $\begin{array}{l}\text { Training pro- } \\
\text { vided }\end{array}$ & $\begin{array}{l}\text { - Use of activity cards } \\
\text { - Leading outdoor play } \\
\text { activities } \\
\text { - Gross motor development }\end{array}$ & $\begin{array}{l}\text { - Use of the resource kit } \\
\text { - Recommendations for } \\
\text { integration of activities into } \\
\text { daily lesson plans } \\
\text { - Use of activity cards } \\
\text { - Strategies to promote } \\
\text { healthy eating }\end{array}$ & $\begin{array}{l}\text { - Workshops on nutrition and } \\
\text { physical activity } \\
\text { - Counseling on physical } \\
\text { activity and healthy eating } \\
\text { - Goal-setting and self- } \\
\text { monitoring }\end{array}$ & $\begin{array}{l}\text { - Delivery of session materials } \\
\text { - Presentation skills }\end{array}$ \\
\hline
\end{tabular}


time. Parent peer educators received a small stipend (up to $\$ 160$ ) to participate in a 10 -hour training and deliver six poster sessions that focused on obesity, physical activity and nutrition guidelines, and strategies for promoting healthy eating and physical activity at home. Parent peer educators approached parents as they arrived to pick up their child and invited them to view the posters. When parents agreed, they were escorted to the area inside the center where the posters were set up. Parents visited posters, interacted with parent peer educators, completed an information scavenger hunt worksheet and received a Take-Home Bag with a storybook from class, family activities, and a developmentally appropriate interactive game. Parents also received a healthy snack for their children $(<150$ calories) after viewing the posters. It took 5-10 minutes for parents to complete these activities.

\section{Study Measures}

We measured children's heights and weights with light clothes and no shoes at pre- and posttest. Two measurements were taken within $0.5 \mathrm{~cm}$ for height and $0.25 \mathrm{~kg}$ for weight discrepancy allowed, and an average was used. $z$-scores for weight and BMI were calculated. ${ }^{25}$

We assessed development of gross motor skills with raw scores from the Learning Achievement Profile Version 3 (LAP-3) conducted by Head Start teachers per federal guideline at the beginning, middle, and end of the school year. LAP-3 is a criterion-based test with strong validity and reliability. ${ }^{36}$

Children's outdoor play behaviors were assessed by pedometry on 3 consecutive days simultaneously at all centers at pretest, three mid-study points, and posttest. The first 5 boys and 5 girls whose classroom arrived first in the outdoor area were given a pedometer to wear during play periods. A physical activity score was calculated as total step counts divided by duration of observed play period. A higher score equals higher levels of mobility and movements.

We used an aggregated plate waste method to monitor dietary intake at lunch on 3 consecutive days at pre- and posttest. ${ }^{37}$ We measured the weight of food items served and uneaten ("wasted") portions by table. Total food mass minus "wasted" food, divided by the number of children at a table, equaled the average "food intake" per table. Dietary intake was analyzed using Nutrition Data System for Research (NDSR) with menus provided by Head Start food services. Number of servings of the food groups (fruits and vegetables, low-fat milk, grains, and meats) consumed per child was estimated after adjusting for numbers of children and gender ratio at each table.

We used several process evaluation tools to monitor fidelity and feasibility of Miranos!. Teachers completed a biweekly report on supplemental classroom activities (frequency, time of the day, location of use, and problems) that served as an assessment of protocol implementation fidelity. To evaluate feasibility, teachers and paraprofessionals also completed a Miranos! poststudy survey evaluating satisfaction and usefulness of staff training and intervention materials and their observation of children's responses. Teachers also completed a survey on staff wellness participation and self-reported changes in diet and physical activity behaviors and health conditions.

Fifty-five percent of parents of the consent children completed a posttest survey without incentive that provided reports of their children's diet and physical activity behaviors at home. The data were collected at both intervention sites and the comparison site. Intercept interviews with intervention parents/guardians assessed parental awareness of and exposure to Miranos! at posttest (data not presented) at the two intervention sites. Finally, we conducted separate focus group discussions with parents, Head Start directors, teachers, and paraprofessionals to gather their feedback on Miranos! at posttest.

\section{Statistical Analysis Plan}

General Linear Models with planned contrasts tested the effect of Miranos! on changes of body weight and gross motor skills development between the two treatment group children and comparison children from pre- to posttest. Covariates (gender, age, and pretest measure, etc.) were included in the model when appropriate. We set the significance level at $p<0.05$ with a one-tailed test because our early pilot study results showed favorable impacts in body weight, gross motor development, and parentreported outcomes. ${ }^{20}$ We analyzed food consumption at lunch from plate waste and pedometer counts from outdoor play observation the same way. Chi-squared tests compared differences in children's behavior at home from the poststudy parental surveys between treatment and comparison groups ( $p<0.05$ one-sided test). Categorical measures from process evaluation (teacher self-reports of program implementation and staff wellness survey) on differences between the two treatment conditions were analyzed using a chi-squared test with $p<0.05$ (two-tailed test). A $t$-test was used to assess differences between the two treatment conditions in scale scores of children's responses to Miranos! with signifiance at $p<0.05$ (two-tailed test).

\section{Results}

Of the 384 children tested at pretest, $88 \%$ were retested at posttest, which constituted the sample for this study. Response rate of poststudy parent surveys was lower $(p<$ 0.05 ) in the center-based intervention group than the two other groups. At pretest, $17 \%$ of the children were classified as obese, $20 \%$ overweight, $62 \%$ normal weight, and $1 \%$ underweight. ${ }^{25}$ The percentage of children with obese and overweight status in this study sample was lower than those reported in regional surveys and our earlier pilot research. There was no difference in children's characteristics between treatment conditions at pretest (see Table 1) as well as between children who were retested and those who were not retested at the posttest (data not shown). 


\section{Primary Study Outcomes}

Per CDC's Growth Chart, ${ }^{25}$ the children in the intervention and comparison groups were heavier than expected at pre- and posttest with a $0.3-0.7$ standard deviation (SD) above children of similar age and gender (see weight based $z$-scores in Table 3). However, the gain in weight $z$-score for age and gender $(p<0.04)$ was significantly less for the combined center- and home-based intervention children than comparison children. There was no significant difference in changes in weight and BMI $z$-scores between the center-based intervention and comparison groups. At posttest, children in the center-based $(p<0.01)$ and combined center- and home-based intervention $(p<$ 0.001 ) showed higher levels of gross motor skills development than comparison children, based on raw scores of gross motor assessment from LAP-3 (see Table 3).

\section{Children's Responses to Miranos! Intervention}

On the basis of the pedometry data, children in the intervention centers increased their levels of outdoor play intensity over the five observation time points, whereas comparison children maintained the intensity at pretest level. Specifically, active play levels were significantly higher $(p<0.05)$ in children in both treatment groups at mid-test 2 and posttest, and in the center-based intervention children at mid-test 1, compared to comparison children (see Fig. 2).

Results of plate waste analyses showed that children in the treatment groups increased consumption of fruit, vegetables, and low-fat milk, compared to the comparison group at posttest. Center- and home-based intervention children consumed significantly more fruit and vegetables (0.19 serving; $p<0.05)$ and low-fat milk (0.06 serving; $p<$ $0.006)$ than comparison children at posttest. Center-based

\begin{tabular}{|c|c|c|c|c|c|c|c|c|c|}
\hline & & \multicolumn{2}{|c|}{$\begin{array}{c}\text { Comparison } \\
(\text { Com; } n=69)\end{array}$} & \multicolumn{2}{|c|}{$\begin{array}{l}\text { Center-based } \\
\text { intervention } \\
(\mathrm{CBI} ; n=118)\end{array}$} & \multicolumn{2}{|c|}{$\begin{array}{l}\text { Center- and home- } \\
\text { based intervention } \\
(\mathrm{C} \text { and } \mathrm{HBI} ; n=66)\end{array}$} & \multirow{2}{*}{$\begin{array}{l}\text { Adjusted } \\
\text { difference } \\
\text { between } \\
\text { Com and CBI }\end{array}$} & \multirow{2}{*}{$\begin{array}{l}\text { Adjusted } \\
\text { difference } \\
\text { between } \\
\text { Com and } \\
\mathrm{C} \text { and } \mathrm{HBI}\end{array}$} \\
\hline & & Mean & SD & Mean & SD & Mean & SD & & \\
\hline \multirow[t]{2}{*}{ Weight $(\mathrm{kg})^{\mathrm{a}}$} & Pretest & 17.69 & 3.54 & 17.38 & 3.37 & 17.59 & 3.36 & \multirow{2}{*}{$\begin{array}{c}-0.02 \\
\text { (NS) }\end{array}$} & \multirow{2}{*}{$\begin{array}{c}-0.13 \\
(p<0.08)\end{array}$} \\
\hline & Posttest & 19.30 & 3.93 & 18.76 & 3.80 & 18.89 & 3.94 & & \\
\hline \multirow{2}{*}{$\begin{array}{l}\text { Weight } z \text {-score for } \\
\text { age and gender }\end{array}$} & Pretest & 0.49 & 1.17 & 0.36 & 0.97 & 0.33 & 1.10 & \multirow{2}{*}{$\begin{array}{r}-0.01 \\
\text { (NS) }\end{array}$} & \multirow{2}{*}{$\begin{array}{c}-0.06 \\
(p<0.04)\end{array}$} \\
\hline & Posttest & 0.58 & 1.17 & 0.39 & 1.00 & 0.30 & 1.10 & & \\
\hline \multirow{2}{*}{$\begin{array}{l}\text { BMI z-score for age } \\
\text { and gender }\end{array}$} & Pretest & 0.70 & 1.32 & 0.65 & 0.99 & 0.62 & 1.11 & \multirow{2}{*}{$\begin{array}{l}-0.04 \\
\text { (NS) }\end{array}$} & \multirow{2}{*}{$\begin{array}{c}-0.09 \\
(p<0.09)\end{array}$} \\
\hline & Posttest & 0.81 & 1.16 & 0.79 & 0.94 & 0.68 & 1.01 & & \\
\hline \multirow{2}{*}{$\begin{array}{l}\text { Score of gross } \\
\text { motor development }\end{array}$} & Pretest & 33.44 & 11.90 & 38.87 & 11.76 & 39.22 & 9.50 & \multirow{2}{*}{$\begin{array}{c}0.79 \\
(p<0.01)\end{array}$} & \multirow{2}{*}{$\begin{array}{c}1.15 \\
(p<0.001)\end{array}$} \\
\hline & Posttest & 42.19 & 9.44 & 47.68 & 6.24 & 48.28 & 5.17 & & \\
\hline \multicolumn{10}{|c|}{ aOne-sided significance test; adjusted for age, gender, and pretest measure; no significant group or gender difference at pretest. } \\
\hline \multirow{2}{*}{\multicolumn{10}{|c|}{$\begin{array}{l}\text { 'One-sided significance test; adjusted for pretest measure; no significant group or gender difference at pretest. } \\
\text { 'One-sided significance test; adjusted for age and pretest measure; significant difference between } \mathrm{CBI} \text { and } \mathrm{C} \text { and } \mathrm{HBI}(p<0.003) \text { at pretest; } \\
\text { no significant gender difference at pretest. }\end{array}$}} \\
\hline & & & & & & & & & \\
\hline \multicolumn{10}{|c|}{ SD, Standard deviation; NS, not significant. } \\
\hline
\end{tabular}

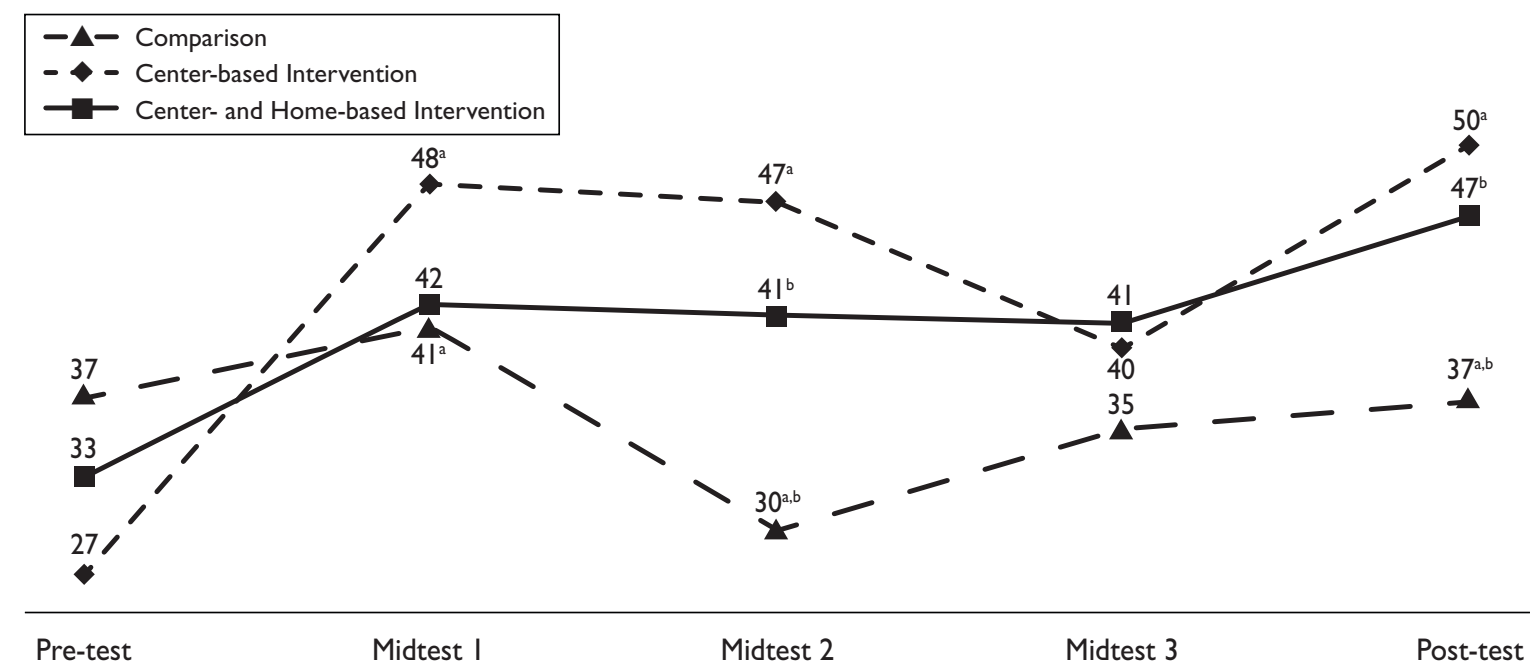

Figure 2. Children's levels of physical activity (steps/minute) during daily outdoor play period over 5 time points based on pedometry. Significant group difference at each time point is notated by the same letter (one-tail test, $p<0.05$ ). 
intervention children consumed significantly more grain products $(0.15$ serving; $p<0.05)$ than comparison children. No significant change in meat consumption was observed.

More than $60 \%$ of intervention teachers and paraprofessionals "strongly agreed" that children responded positively to intervention activities based on the poststudy survey in the intervention centers (see Table 4). Most of the reported responses in the combined center- and homebased intervention children were stronger statistically than the center-based intervention children (see Fig. 3).

\section{Evaluation of Teacher Development and Staff Wellness Program}

More than $90 \%$ of Head Start staff in the intervention centers agreed or strongly agreed that the intervention training, activities, equipment, supplies, and logistic support provided by the research team helped implement classroom and outdoor/gross motor activities in the poststudy survey of teachers and paraprofessionals.

Most staff participated in the voluntary wellness program (see Table 5): $79 \%$ in health screenings, $86 \%$ in

\begin{tabular}{|c|c|c|c|}
\hline & All & $\begin{array}{l}\text { Center-based } \\
\text { intervention }\end{array}$ & $\begin{array}{l}\text { Center- and } \\
\text { home-based } \\
\text { intervention }\end{array}$ \\
\hline Children recognized and associated health messages with Miranos! ${ }^{\text {b }}$ & $3.59(0.66)$ & $3.42(0.72)$ & $4.00(0.00)$ \\
\hline Children responded positively to the health messages from Míranos! $!^{b}$ & $3.69(0.56)$ & $3.56(0.61)$ & $4.00(0.00)$ \\
\hline Children enjoyed classroom activities from Míranos $!^{\mathrm{b}}$ & $3.78(0.42)$ & $3.69(0.47)$ & $4.00(0.00)$ \\
\hline Children knew the difference between sometime and anytime foods ${ }^{b}$ & $3.50(0.66)$ & $3.29(0.69)$ & $4.00(0.00)$ \\
\hline Children enjoyed the Race to Health Contest ${ }^{\mathrm{b}}$ & $3.76(0.48)$ & $3.66(0.54)$ & $4.00(0.00)$ \\
\hline Children tried to eat more fruit during lunch ${ }^{\mathrm{b}}$ & $3.74(0.54)$ & $3.63(0.61)$ & $4.00(0.00)$ \\
\hline Children tried to eat more vegetables during lunch ${ }^{\mathrm{b}}$ & $3.56(0.78)$ & $3.41(0.87)$ & $3.92(0.27)$ \\
\hline Children tried to eat more fruit during snacks ${ }^{b}$ & $3.70(0.55)$ & $3.58(0.62)$ & $4.00(0.00)$ \\
\hline Children tried to eat more vegetables during snacks ${ }^{b}$ & $3.57(0.66)$ & $3.42(0.72)$ & $3.92(0.27)$ \\
\hline Children tried to drink more milk & $3.82(0.44)$ & $3.75(0.5 \mathrm{I})$ & $4.00(0.00)$ \\
\hline Children tried to drink more water ${ }^{b}$ & $3.78(0.47)$ & $3.69(0.54)$ & $4.00(0.00)$ \\
\hline
\end{tabular}

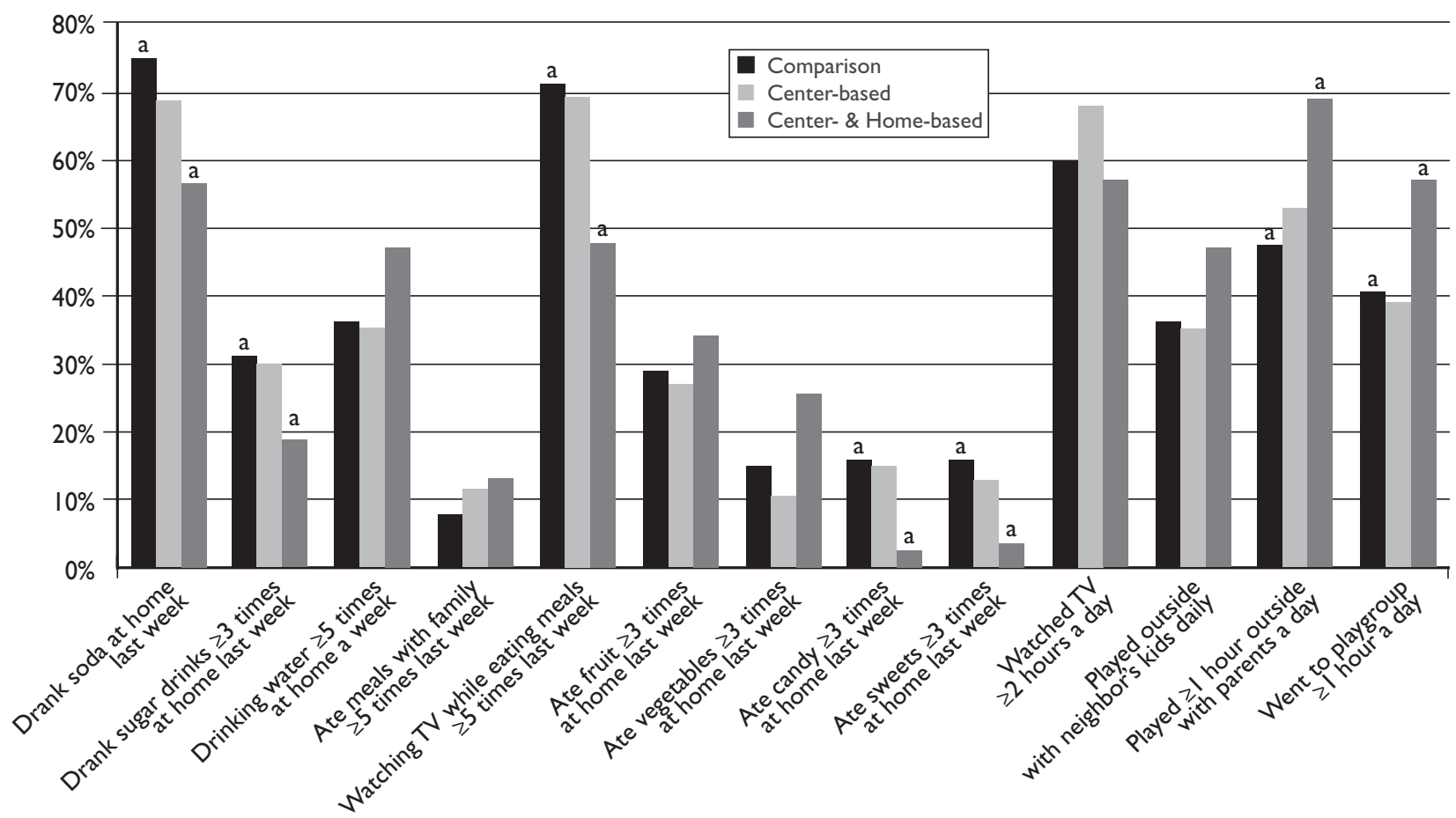

Figure 3. Reported children's dietary and physical activity behaviors at home based on the post-test parent survey. Significant group difference is notated by the same letter (one-tail chi-squared test, $p<0.05$ ). 
walk contest, $79 \%$ in nutrition training, $71 \%$ in resistance band exercise, and $89 \%$ in reading Miranos! Health Newsletters. Participating staff reported improved knowledge and skills in physical activity (91\%), nutrition (91\%), and obesity and diabetes prevention (84\%). More than $70 \%$ reported improved weight, cholesterol, and blood pressure based on health screening results.

\section{Evaluation of Fidelity and Feasibility}

Overall, there was a high level of fidelity implementing planned program activities, according to a biweekly evaluation of supplemental classroom activities completed by $99 \%$ of intervention center teachers. Teachers completed $83 \%$ (range, $72 \%$ to $98 \%$ ) of planned classroom activities. Teachers used $57 \%$ (range, $22-88 \%$ ) of the classroom activities two or more times a week, led by movement music CDs $(88 \%)$. Few teachers $(1.6 \%$; ranging $1 \%-3 \%)$ reported problems using activities.

Average participation at the six peer-led parent education sessions was high $(\mathrm{M}=80 \%, \mathrm{SD}=7.9)$. Focus groups indicated that parents enjoyed receiving information from the parent peer educators and considered them trusted, reliable information sources, and they appreciated the session format, schedule, and materials.

\section{Discussion}

Miranos! targeted the child care center and home to create a culturally appropriate, health-conducive envi- ronment that produced significant impacts on gross motor development and physical activity and dietary behaviors and showed promising effect on controlling excessive weight gain among Latino Head Start children at risk for obesity. The impacts were greater among children who received a combined center- and home-based intervention.

Interventions in childcare centers, which provide care to half of U.S. preschool children, have proven, albeit limited, effectiveness in health promotion and offer a natural setting for obesity prevention. ${ }^{38-41}$ The small body of literature has generally showed significant impacts on physical activity and dietary behaviors and only limited success impacting body weight in preschool children. One comprehensive obesity intervention reported significant BMI reductions among AfricanAmerican preschool children but no changes in physical activity and dietary outcomes, ${ }^{42}$ and no weight change in Latino children that was attributed to lack of cultural integration. ${ }^{43}$ A school-based randomized trial in England reported significant effects on gross motor development but not on weight in children ages $3-6 .{ }^{44}$ An environmental intervention in 84 childcare centers only had positive impacts on physical activity and nutritional practices in intervention centers that implemented more than $75 \%$ of intervention activities. Similar results were reported in studies in family childcare homes. ${ }^{45,46}$ Another study showed that intervention preschool children significantly lowered their cholesterol level and improved diet and physical activity, but no significant impact on

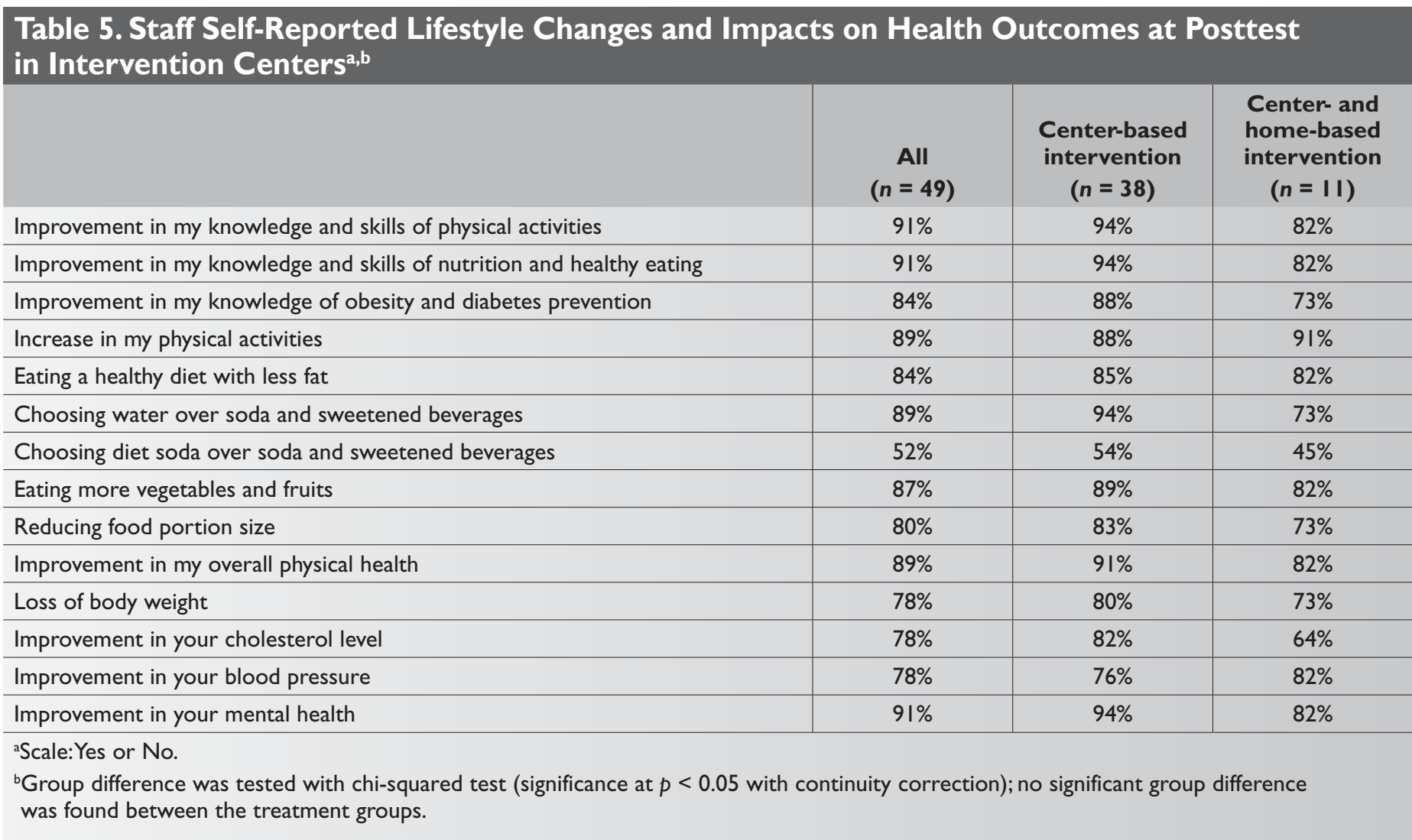


children's weight was found. ${ }^{38}$ Our study demonstrates similar findings among Latino children who were mostly in the normal weight range, using directly measured behavioral changes in physical activity by pedometry and diet by plate waste test.

The promising outcomes of Miranos! could be attributed to several program features. First, we used age-appropriate, interactive, and appealing materials (Sesame Street characters) to introduce healthy eating and physical activity. ${ }^{31}$ Young children are receptive to messages from familiar media or cartoon characters ${ }^{47,48}$ with fun, hands-on activities delivered in an interactive learning setting. ${ }^{26}$ Second, using outdoor activity lesson plans featuring Activity Cards and play equipment increased children's opportunities for moderateto-vigorous activities and gross motor development. ${ }^{49,50}$ Traditional free outdoor play tends to do neither. ${ }^{8,51}$ Third, training teachers in obesity, physical activity, and nutrition filled a competency gap among many childcare professionals. The training, alongside a widely participated staff wellness program, provided staff motivation and skills to engage children and create a supportive health environment. ${ }^{7,8,52}$ Fourth, exposure to Miranos! was high in children in both treatment groups largely due to participation of and support from Head Start directors, staff, and central office personnel. This support reduced implementation barriers and led to high fidelity of implementation and protocol compliance. Finally, we tailored Miranos! to our study population by incorporating values and experience relevant to Latino culture (i.e., family orientation, traditional diet and physical activities, bilingual delivery of information, and need of obesity prevention knowledge) into program design and by refining and reformatting activities based on the results of process evaluation and focus group discussions from our previous pilot studies in the same study population. The importance of cultural tailoring of obesity prevention has been shown in Salsa, Sabor y Salud, a family-centered program designed to promote physical activity and healthy eating for Latino families with young children. ${ }^{53}$

We did not intend to compare effectiveness of a centerbased vs. a combined center- and home-based intervention; however, the latter had more favorable outcomes. Although home-based interventions are logistically challenging and sparse in childcare settings, ${ }^{12,21}$ we speculate that the Miranos! home-based intervention contributed to increased physical activity and healthy eating opportunities at home because we did not find significant difference in center-based intervention activities between the two intervention groups. This success stems most likely from the increases in parental health literacy on obesity prevention knowledge and skills ${ }^{32}$ from culturally sensitive, interactive intervention activities that were delivered by trained parent peer educators. ${ }^{22,44}$ Parents' appreciation of peer-led learning supports the acceptability of future peer-led programs in this setting.
The study had several weaknesses that limit external validity and generalizability. First, it was not a randomized study and used a convenience sample. We also did not assess sampling bias because we did not have access to information on children who did not participate in the study. Second, gross motor skill, assessed by Head Start teachers with a criterion reference measure, should be replicated with a normed gross motor skill test in the future. Third, we found a modest but significant reduction in weight $z$-score, but not in BMI $z$-scores. Fourth, the extent of the environmental changes was limited by existing Head Start policy and regulatory practices (i.e., unalterable menus and time lengths for outdoors play) and accessibility to physical activity and healthy foods at home. As a result, the changes in physical activity and dietary behaviors were likely inadequate to influence the excessive gain in body weight in intervention children. Future interventions must engage the Head Start program's administrative body during intervention planning to incorporate policy change to support system-wide behavior changes. ${ }^{7}$

\section{Conclusions}

Miranos! is a unique example of using a systems approach to create change at multiple levels and synergize multiple components to promote changes in preschool children's physical activity and dietary behaviors, ${ }^{28,54}$ given the limited research targeting this population group ${ }^{55,56}$ Extensive feedback and process evaluation data indicated that Miranos! was received positively by Head Start children, parents, administrators, and teachers and was feasible for integration into Head Start programs. The most consistent changes of the targeted behaviors occurred in children who received the combined center- and home-based intervention. Findings should be replicated in a randomized controlled trial to examine its efficacy. ${ }^{12}$

\section{Acknowledgments}

Funding for this project was provided by the San Antonio Life Sciences Institute, San Antonio, TX, and the International Life Sciences Institute Research Foundation, Washington, DC. The research team wants to thank the children, parents, directors, teachers, and staff of Head Start and the Family Service Association of San Antonio (Ms. Nancy Hard and Ms. Melissa Williamson) who participated in and/or supported this project. Our appreciation also goes to Mr. Cliff Despres who edited the manuscript and our graduate assistants and intern students who helped with intervention delivery and data collection.

\section{Author Disclosure Statement}

No competing financial interests exist. 


\section{References}

1. CDC Obesity-United States, 1988-2008. Morbidity and Mortality Weekly Report 2011;60:73-77.

2. Piziak V, Morgan-Cox M, Tubbs J, et al. Elevated body mass index in Texas Head Start children: A result of heredity and economics. South Med J 2010;103:1219-1222.

3. Troiano RP, Briefel RR, Carroll MD, et al. Energy and fat intakes of children and adolescents in the United States: Data from the national health and nutrition examination surveys. Am J Clin Nutr 2000;72:1343S-1353S

4. Kranz S, Siega-Riz AM, Herring AH. Changes in diet quality of American preschoolers between 1977 and 1998. Am J Public Health 2004;94:1525-1530.

5. Trost SG, Sirard JR, Dowda M, et al. Physical activity in overweight and nonoverweight preschool children. Int $J$ Obes Relat Metab Disord 2003;27:834-839.

6. Tucker P. The physical activity levels of preschool-aged children: A systematic review. Early Child Res Q 2008;23:547-558.

7. Story M. The role of child care settings in obesity prevention. The Future of Children/Center for the Future of Children, the David and Lucile Packard Foundation 2006;16:143-168.

8. Bower JK, Hales DP, Tate DF, et al. The childcare environment and children's physical activity. Am J Prev Med 2008;34:23-29.

9. Clarke WR, Lauer RM. Does childhood obesity track into adulthood? Crit Rev Food Sci Nutr 1993;33:423-430.

10. Freedman DS, Khan LK, Mei Z, et al. Relation of childhood height to obesity among adults: The Bogalusa Heart Study. Pediatrics 2002;109:e23.

11. De Kroon MLA, Renders CM, Van Wouwe JP, et al. The Terneuzen Birth Cohort: BMI changes between 2 and 6 years correlate strongest with adult overweight. PLOS ONE 2010;5:e9155.

12.Birch LL, Ventura AK. Preventing childhood obesity: What works? Int J Obesity (Lond) 2009;33(Suppl 1):S74-S81.

13. National Institutes of Health. Methods for voluntary weight loss and control. NIH Technology Assessment Conference Panel. Ann Intern Med 1992;116:942-949.

14. Sumithran P, Prendergast LA, Delbridge E, et al. Long-term persistence of hormonal adaptations to weight loss. $N$ Engl J Med 2011;365:1597-1604.

15.Larson N, Ward DS, Neelson SB, et al. What role can child-care settings play in obesity prevention? A review of the evidence and call for research efforts. J Am Diet Assoc 2011;111:13431362.

16. Hughes CC, Gooze RA, Finelstein DM, et al. Barriers to obesity prevention in Head Start. Health Affairs (Millwood) 2010;29:454462.

17. Epstein LH, Valoski AM, Kalarchian MA, et al. Do children lose and maintain weight easier than adults: A comparison of child and parent weight changes from six months to ten years. Obes Res 1995;3:411-417.

18.Epstein LH, Valoski AM, Wing RR, et al. Ten-year follow-up of behavioral, family-based treatment for obese children. JAMA 1990;264:2519-2523.

19. Salmon J, Booth ML, Phongsavan P, et al. Promoting physical activity participation among children and adolescents. Epidemiol Rev 2007;29:144-159.

20. Yin Z, Ramirez A, Kibbe DL. Preliminary Report of Phase 1 (2009-2010) of Juntos y Saludables (Get Healthy Together): An Obesity/Diabetes Prevention Project for Preschool Children. The University of Texas at San Antonio and University of Texas Health Science Center San Antonio: San Antonio, TX, 2010.
21.Birch LL, Davison KK. Family environmental factors influencing the developing behavioral controls of food intake and childhood overweight. Pediatr Clin North Am 2001;48:893-907.

22. Bond M, Wyatt K, Lloyd J, et al. Systematic review of the effectiveness and cost-effectiveness of weight management schemes for the under fives: A short report. Health Technol Asses 2009;13:175 iii.

23. Baumann M, Chance W. Community Survey, 2008: Final Report. City of San Antonio. 2009.

24. City of San Antonio DoCI. San Antonio and Bexar County Head Start Program. 2009.

25. Centers for Disease Control and Prevention. CDC Growth Charts: United States. 2000. Available at http://www.cdc.gov/nchs/about/ major/nhanes/growthcharts/charts.htm/. Last accessed August 10, 2012.

26. Birch LL. Development of food acceptance patterns in the first years of life. Proc Nutr Soc 1998;57:617-624.

27. Hesketh KD, Campbell KJ. Interventions to prevent obesity in $0-5$ year olds: An updated systematic review of the literature. Obesity (Silver Spring) 2010;18(Suppl 1):S27-S35.

28.Huang TT, Drewnosksi A, Kumanyika S, et al. A systems-oriented multilevel framework for addressing obesity in the 21 st century. Prev Chronic Dis 2009;6:A82.

29. Sanders LM, Federico S, Klass P, et al. Literacy and child health: A systematic review. Arch Pediatr Adolesc Med 2009;163:131-140.

30. Yin HS, Johnson M, Mendelsohn AL, et al. The health literacy of parents in the United States: A nationally representative study. Pediatrics 2009;124(Suppl 3):S289-S298.

31. DeWalt DA, Hink A. Health literacy and child health outcomes: A systematic review of the literature. Pediatrics 2009;124(Suppl 3):S265-S274

32. Sanders LM, Shaw JS, Guez G, et al. Health literacy and child health promotion: Implications for research, clinical care, and public policy. Pediatrics 2009;124(Suppl 3):S306-S314.

33. Ward DS. Physical activity in young children: The role of child care. Med Sci Sports Exerc 2010;42:499-501.

34. Sesame Workshop. The Healthy Habits for Life Child Care Resource Kit. 2010. Available at http://kidshealth.org/classroom/ index.jsp?Grade $=\mathrm{cc} \&$ Section $=\mathrm{hhfl} /$. Last accessed August 10, 2012.

35. National Academy of Sciences. Health Literacy: A Prescription to End Confusion. In: Nielsen-Bohlman L, Panzer AM, Kindig DA (eds). National Academy of Sciences. 2004. Available at www. nap.edu/openbook.php?isbn $=0309091179 /$. Last accessed August 10, 2012

36. Hardin BJ, Peisner-Feinberg ES. The Learning Accomplishment Profile-Third Edition (LAP-3)e. Chapel Hill Training Outreach Project, Inc., 2004.

37. Jacko C, Dellava J, Ensle K, et al. Use of the plate-waste method to measure food intake in children. $J$ Extension 2007;45:6RIB7.

38. Williams CL, Bollella MC, Strobino BA, et al. "Healthy-start": Outcome of an intervention to promote a heart healthy diet in preschool children. J Am Coll Nutr 2002;21:62-71.

39. Webster-Stratton C, Jamila Reid M, Stoolmiller M. Preventing conduct problems and improving school readiness: Evaluation of the Incredible Years Teacher and Child Training Programs in high-risk schools. J Child Psychol Psychiatry 2008;49:471-488.

40. Roberts L, Jorm L, Patel M, et al. Effect of infection control measures on the frequency of diarrheal episodes in child care: A randomized, controlled trial. Pediatrics 2000;105:743-746.

41. Roberts L, Smith W, Jorm L, et al. Effect of infection control measures on the frequency of upper respiratory infection in child care: A randomized, controlled trial. Pediatrics 2000;105:738-742. 
42. Fitzgibbon ML, Stolley MR, Schiffer L, et al . Two-year follow-up results for Hip-Hop to Health Jr.: A randomized controlled trial for overweight prevention in preschool minority children. $J$ Pediatr 2005;146:618-625.

43. Fitzgibbon ML, Stolley MR, Schiffer L, et al. Hip-Hop to Health Jr. for Latino preschool children. Obesity (Silver Spring) 2006;14:1616-1625.

44. Reilly JJ, Kelly L, Montgomery C, et al. Physical activity to prevent obesity in young children: Cluster randomised controlled trial. Br Med J 2006;333:1041-1043.

45. Trost SG, Messner L, Fitzgerald K, et al. A nutrition and physical activity intervention for family child care homes. Am J Prev Med 2011;41:392-398.

46. Trost SG, Messner L, Fitzgerald K, et al. Nutrition and physical activity policies and practices in family child care homes. Am J Prev Med 2009;37:537-540.

47.Lapierre MA, Vaala SE, Linebarger DL. Influence of licensed spokescharacters and health cues on children's ratings of cereal taste. Arch Pediatr Adolesc Med 2011;165:229-234.

48. Roberto CA, Baik J, Harris JL, et al. Influence of licensed characters on children's taste and snack preferences. Pediatrics 2010;126:88-93.

49. National Association for Sport and Physical Education. Moving into the Future: National Standards for Physical Education 2nd Edition ed. NASPE Publishers: Reston, VA, 2004.

50.Williams HG, Pfeiffer KA, O'Neill JR, et al. Motor skill performance and physical activity in preschool children. Obesity (Silver Spring) 2008;16:1421-1426.

51.Pate RR, Pfeiffer KA, Trost SG, et al. Physical activity among children attending preschools. Pediatrics 2004;114:1258-1263.
52. Dowda M, Pate RR, Trost SG, et al. Influences of preschool policies and practices on children's physical activity. $J$ Community Health 2004;29:183-196.

53. The National Latino Children's Institute. Salsa, Sabor y Salud. Available at www.nlci.org/Salsa-sabor-y-salud/The-Program.html/. Last accessed August 10, 2012.

54. Pronk NP, Boucher J. Systems approach to childhood and adolescent obesity prevention and treatment in a managed care organization. Int J Obes Relat Metab Disord 1999;23:S38-S42.

55.Guo SS, Wu W, Chumlea WC, et al. Predicting overweight and obesity in adulthood from body mass index values in childhood and adolescence. Am J Clin Nutr 2002;76:653-658.

56.Institute of Medicine. Weighing the Options: Criteria for Evaluating Weight-Management Programs. National Academy Press: Washington DC, 1995.

Address correspondence to: Zenong Yin, Ph.D.

Loretta J. Lowak Clarke Distinguished Professor in Health and Kinesiology University of Texas at San Antonio College of Education and Human Development Department of Health and Kinesiology One UTSA Circle San Antonio, TX 78249

E-mail: zenong.yin@utsa.edu 